\section{Ibura: águas férteis de onde nascem cidadania, antropologia e ação}

Parry SCOTT \& Marion Teodósio de QUADROS. A diversidade do Ibura: gênero, geração e saúde num bairro popular do Recife. Recife, Editora da Universidade Federal de Pernambuco, 2009. 269 páginas.

\section{Soraya Fleischer}

"Nascente de água" ou "água que arrebenta". Acepçōes relacionadas com a água que nasce ou se movimenta estão na raiz do nome "Ibura", bairro significativo da metrópole do Recife, que serve de cenário para o presente livro. O Ibura, neste final da primeira década do século XXI, reúne cerca de 100 mil habitantes, o que representa 6,6\% da população da cidade, sendo "maior do que $90 \%$ das cidades do Estado de Pernambuco" (p. 34). Em geral, o bairro reúne famílias com renda média em torno de 2,5 salários mínimos, e predomina o baixo grau de instrução (pp. 29-30). Entre as dezenas de bairros do Recife, um forte estigma de violência tem sido vinculado ao Ibura, enquanto seus moradores insistem que viver ali é agradável, pacato e calmo. São estes mesmos moradores que têm se mobilizado em organizaçôes sociais e movimentos populares, variados em termos de tamanho, missão, estratégia, história, e se revelam como protagonistas fundamentais para "garantir as condiçôes de infraestrutura do bairro" (p. 25). São estes atores coletivos, inclusive, que conseguiram mobilizar e atrair a construção de habitaçóes populares, do tipo Cohab, logo no início da instalação do bairro, sobretudo para vítimas de sucessivas enchentes e desabastecimentos de água que assolam essa região. As águas do Ibura podem ser, portanto e paradoxalmente, seu início e seu fim.

É justamente essa diversidade de imagens, atores e atividades que marcam o bairro e batizam o livro e sua proposta dorsal: "Não foi justificativa teórica. O termo [da diversidade] nos pareceu adequado para explicar uma apropriação prática que refere a uma série de características e modos de vida bastante diferenciados convivendo e se interrelacionando em um espaço comum" (p. 7). "Diversidade sugere uma tensão permanente no lugar, mas que sempre deixa uma brecha para uma convivência possível, mesmo que se ofusque parcialmente outro realce possível, as desigualdades" (p. 8).

Essa diversidade tem sido apreendida nos últimos quinze anos de interação, desde 1995, entre o Ibura e o Núcleo de Família, Gênero e Sexualidade (Fages) da UFPE. Os onze capítulos do livro apresentam uma gama de pesquisadores que estão ou passaram, em algum momento de sua formação, pelo Fages, já que aparecem tanto como autores dos capítulos quanto como referências bibliográficas importantes de pesquisas anteriores realizadas no mesmo bairro. As pesquisas foram financiadas para compreender questôes específicas e demandadas pelo Ibura, oriundas de artigos apresentados e publicados em congressos e periódicos acadêmicos ou de dissertações e teses defendidas na UFPE. Assim, o livro apresenta excelentes estudos antropológicos sobre o Ibura, mas é também, por fim, uma sistematização da memória e da trajetória de um consolidado núcleo de pesquisa. É, a um só tempo, um retorno aprofundado e complexo do que o Fages tem realizado neste bairro e um convite para reinventarmos a antropologia e seus resultados.

Esta coletânea constitui-se de uma introdução e quatro partes, sendo a última um conjunto de três anexos. Escritos por catorze autores e autoras principalmente da antropologia (mas também da medicina, psicologia, sociologia), os textos nascem de várias técnicas de pesquisa: etnografia, questionários, amostras, estatísticas, entrevistas, grupos de discussão. E, de forma inovadora e aplicada, "reúne materiais para orientar um trabalho de desenvolvimento de ações concretas que possam ser realizadas pelos residentes dos bairros e por organizaçōes que trabalham a favor deles" (p. 9). A seguir, comento as quatro partes que compõem o livro.

A primeira parte, intitulada "O bairro do Ibura", é composta por dois capítulos, ambos assinados pelos professores que organizam o livro. $\mathrm{O}$ primeiro apresenta uma contextualização histórica, social e cultural da diversidade identificada no Ibura e serve como pano de fundo para o que segue no livro. Mapas e fontes demográficas ajudam a entender a presença e a longevidade femi- 
nina das moradoras (em relação aos moradores), a quantidade expressiva de jovens, mesmo com o envelhecimento expressivo da população, a grande proporção de chefias familiares femininas e o insistente nível de desemprego que orienta escolhas e faltas de escolhas na região. Apesar de parecer com outros bairros periféricos de grandes metrópoles, os autores lembram que o Ibura "é muito mais do que um bairro dormitório" (p. 32). No segundo capítulo dessa sessão, conhecemos as características de saúde no bairro e suas relações com as questões de gênero. São apresentadas as principais causas de mortalidade e morbidade da população. As equipes do Fages têm notado que, nos últimos anos, o Pacs abriu caminho a uma espécie de "Programa de Saúde da Família - PSF generalista”, e o atendimento - voltado principalmente para mulheres, bebês e idosos - tem dado lugar às ações de promoção e educação em saúde. Como consequências destas mudanças, de um lado, mesmo com a presença de muitas equipes do PSF, a ênfase do cuidado tem sido em patologias orgânicas, no tratamento individual e curativo e no planejamento familiar. De outro lado, as mulheres, sobretudo aquelas em idade reprodutiva (gestantes e nutrizes), continuam como principal (e quase único) público-alvo dos serviços de saúde. Essa política ao mesmo tempo afasta homens e jovens, já que são tidos pelos profissionais da saúde como naturalmente "associados à violência", e dificulta a geração de dados epidemiológicos sobre eles.

"Gênero e geração", a segunda parte do livro, reúne três capítulos. A partir de uma amostra aleatória de dezoito famílias e ao cruzar os indicadores de tamanho, composição e chefia familiar com pluralismo religioso, Márcia Thereza Couto descobriu que o arranjo familiar predominante é de casal com filhos $(71,6 \%)$ entre as famílias cujos membros compartilham da mesma religião (p. 85). Além disso, o pluralismo religioso tende a ser maior nas famílias que fogem ao "modelo tradicional”, como aquelas chefiadas por mulheres. Embora haja "uma adesão pessoal e voluntária às igrejas evangélicas" (p. 93), essa adesão "responderia por 'desordens' instaladas na família [...] que são resultado do imbricamento entre os referenciais identitários mais amplos - de gênero, geração e curso de vida - e a realidade cotidiana da dinâmica familiar no contexto da pobreza” (p. 94, grifo meu). Valores individualistas parecem conviver com os valores relacionais, mas a família chega ao final como um aspecto centralizador de sentido no bairro.

Mary Alves Mendes mostra como a participação das moradoras do Ibura tem crescido nas esferas de educação, trabalho, política comunitária e movimentos sociais. Estas lideranças, muitas vezes as únicas e assíduas provedoras da renda domésti$\mathrm{ca}$, tinham com desafio conciliar a vida familiar e o trabalho comunitário, como outras pesquisas já revelaram antes. Nesse exercício, negociar questóes coletivas no âmbito público lhes capacitava para enfrentar desigualdades de gênero presentes dentro de casa. A meu ver, o principal problema do capítulo é perpetuar a dicotomia clássica "casa e rua", mesmo que mulheres e homens alternem de forma variada por esses dois espaços. Se, no início do capítulo, dados sustentam os retratos apresentados sobre essas mulheres, ao final, as conclusōes tendem a um tom mais ensaístico do que calcado em resultados concretos da pesquisa.

O capítulo de Parry Scott encerra essa segunda parte do livro com uma densa e inovadora pesquisa sobre os idosos do Ibura. O autor mostra a maneira pela qual os homens mais velhos valorizam o "ficar em casa" como principal atividade recreativa, ao passo que, ao envelhecer, "as mulheres chefes, cônjuges ou dependentes - estendem a sua influência para uma maior densidade de redes de relaçôes de parentes, vizinhos, patrões e de outros mediadores de poder atuantes na cidade, independentemente de serem chefes ou não" (p. 120). Ao contrário do que vimos no capítulo anterior, aqui Scott atualiza o legado de clássicos como Roberto DaMatta e Gilberto Freyre, porque, no Ibura, por exemplo: a) o trabalho feminino questiona "um dos sustentáculos da diferenciação por gênero de casa e rua" (p. 125); b) as mulheres têm ganhado autoridade como chefes de família; c) o desemprego mina as possibilidades dos homens continuarem como provedores; d) o homem "muito mais do que continuar procurando novos recursos na rua que tanto tem contribuído para a sua fragilização", retorna à casa "normalmente portador de algum benefício [assistencial]", o que "representa uma tentativa de 
se apegar à valorização moral da casa, e da recuperação do [seu] espaço masculino nela” (p. 129). Assim, Scott percebe que os idosos invertem o space genderizing (já que as senhoras vão para rua e os senhores voltam para casa). Ainda assim, como Couto mostrou em seu capítulo, a casa e a família, mesmo revisitados, continuam centrais entre os valores desses personagens.

A terceira parte do livro, "Saúde reprodutiva", conta com dois capítulos sobre discursos e práticas dos jovens do Ibura em relação à saúde sexual e reprodutiva. Depois de vários capítulos de contexto, mais ou menos etnográficos, este (assim como o capítulo anterior) é um dos pontos altos do livro, recheado com o que Malinowski chamou de "carne e sangue" das pessoas conhecidas e entrevistadas na pesquisa. Parry Scott, Marion Teodósio e Márcia Longhi realizaram quatro sessões de grupos de discussão com jovens entre 18 e 25 anos. Discursos sobre práticas de "ficar", "namorar" e "casar" - fundamentais para se entender uma moralidade juvenil local - não são apresentados de forma descolada do ambiente social do bairro, já que aspectos sobre alternativas de emprego, relações entre pais e filhos e formação da família também compõem o capítulo. As realidades juvenis são pautadas por dois campos fortemente marcados por gênero: "sexualidade/domesticidade" e "segurança/emprego". Alguns dados demonstram esses dois binômios. Para as moças partícipes da pesquisa, "ficar" custa-lhes a reputação moral e o risco de engravidar; sua "pureza é ainda considerada capital simbólico da honra familiar" (p. 150); e "as prescrições morais quanto ao que a mulher deve ou não fazer na sua vida sexual e reprodutiva continuam fortes após o casamento, sua base é a divisão sexual do trabalho" (p. 155). Já o aborto “é comum e se torna um recurso de controle das relaçôes sociais que evita que [a moça] estabeleça uma relação mais duradoura com um homem que pode se tornar prejudicial à sua reputação e ao seu futuro" (p. 157). Para os rapazes, a grande preocupação é a "manutenção do trabalho ou a falta dele" (p. 142); trabalhar e ser pai revelam-se eixos de construção do ethos masculino. Assim, decisões sobre perder a virgindade e abortar acabam pertencendo a certo campo feminino, enquanto decisões sobre assumir um relacionamento e o trabalho, ao campo masculino.
Ao final do capítulo, há cinco núcleos de demandas emitidas pelos jovens, que podem servir para criar novas formas de interação com essa população, inclusive como políticas públicas.

No outro capítulo dessa parte, Marion e Marta Teodósio analisam o conhecimento e os usos de métodos contraceptivos entre homens do bairro. Aqui, fica clara a intenção de compensar a falta de prioridade que as concepções e a saúde masculinas têm recebido por parte dos serviços de saúde locais, como o segundo capítulo da primeira parte do livro revelou. Um questionário foi aplicado a 141 homens no Ibura, entre 2002 e 2003 . Embora não generalizáveis, os dados mostram semelhanças com comportamentos contraceptivos do homem brasileiro em geral. Segundo a pesquisa, a camisinha e a pílula são os dois métodos mais citados, tanto na "primeira relação sexual" como depois, "em algum momento". A esterilização feminina foi mais mencionada pelos entrevistados de renda mais baixa. A conclusão geral do estudo é que os "homens sexualmente ativos, os que possuem filhos, os pertencentes à faixa etária de 25 a 35 anos e aqueles com maior grau de instrução são os que mais citaram conhecer métodos de contracepção" (p. 183). A literatura tem mostrado que a união conjugal é importante para influenciar o conhecimento contraceptivo entre o universo masculino. A vida sexual ativa também se revela como aspecto fundamental. Os homens casados preferem "métodos femininos" (como a pílula e a ligadura tubária); os homens mais jovens e solteiros preferem "métodos masculinos" (o condom, especialmente). Assim, essa pesquisa revela que os homens não estão ausentes na prática da contracepção, contudo a preferência por métodos "femininos" não se reflete num empoderamento das mulheres no momento da escolha dos mesmos.

Por fim, a quarta parte do livro é composta por três interessantes anexos. No primeiro, encontramos uma descrição metodológica das oficinas de intervenção realizadas com os jovens do Ibura. No segundo, são apresentadas as concepções tidas por estes moradores como relevantes na vivência de gênero, geração e saúde. No último anexo, o livro termina recapitulando a relação de quase duas décadas entre o Fages e os moradores do bairro 
do Ibura, numa perspectiva reflexiva e crítica. Os anexos, mais do que dados brutos de pesquisa, revelam o que tantas vezes sequer aparece nas pesquisas etnográficas de longa permanência, isto é, o que tenho chamado de "andaimes da pesquisa", aqueles elementos de sustentação que vão, paulatinamente, sendo utilizados para construir a relação com nossos interlocutores em campo e depois são retirados pouco a pouco para que apenas as análises e interpretações antropológicas fiquem visíveis em nossos textos. O livro, coeso e coerente, brinda os leitores com várias miradas sobre o bairro do Ibura, sem, contudo, deixar distantes (ou fantasmagóricas) as pessoas (com interesses acadêmicos) que têm estado presentes na vida dessas outras pessoas (moradores da localidade) e vice-versa. A pluralidade que as equipes do Fages mostram ter encontrado no Ibura também se estende ao próprio modus operandi deste núcleo de pesquisa, apontando para a real possibilidade de cidadania, antropologia e ação se embrenharem e se enriquecerem cada vez mais.

SORAYA FLEISCHER é professora do Departamento de Antropologia da Universidade de Brasília - UnB.

E 